\title{
Bite Injuries to the Hand - Review of the Literature
}

\author{
Pradyumna Raval $^{1}$, Wasim Khan ${ }^{2}$, Behrooz Haddad ${ }^{2}$ and Anant Narayan Mahapatra ${ }^{*}, 1$ \\ ${ }^{I}$ Department of Orthopaedic Surgery, Our Lady of Lourdes Hospital, Drogheda, Ireland \\ ${ }^{2}$ University College London Institute of Orthopaedics \& Musculoskeletal Sciences, Royal National Orthopaedic \\ Hospital, Stanmore, UK
}

\begin{abstract}
Patients presenting to the emergency department with bite injuries to the hand sustain them through a number of causes including domesticated as well as stray animal bites, and human bites commonly sustained as a result of violence. The nature of the injuries sustained can be very deceptive. A small tooth mark on the exterior can be a fulminant infection in the tissues deeper down. Tendon injuries, fractures of the metacarpals and phalanges and management of the wound are critical issues faced by a surgeon in dealing with such patients. Similarly the less common bite injuries to the hand, often with disastrous and sometimes fatal complications, do also present to the emergency department. A high incidence of suspicion is needed in dealing with these injuries effectively. In our article we discuss the common as well as uncommon causes of bite injuries to the hand and their management. In addition to reviewing the literature to ascertain the management of such injuries, we also discuss interesting and rare case reports.
\end{abstract}

Keywords: Antibiotics, bites, Eikenella corrodens, hand, pasteurella multocida,

\section{INTRODUCTION}

Bite injuries frequently involve the hand and represent a heterogonous group of injuries. The patients presenting to the emergency department with bite injuries to the hand sustain them through a number of causes including domesticated as well as stray animal bites. These bite injuries can be sustained anywhere, from the relative safety of the patient home environment to more exotic and extreme environments across the World. The literature has many interesting cases of bite injuries to the hand. Human bites are commonly sustained as a result of violence. Similarly the less common animal bite injuries to the hand, often with disastrous and sometimes fatal complications, do also present to the emergency department. The nature of all of these injuries can be very deceptive. A small tooth mark on the exterior can be hiding a fulminant infection in the tissues deeper down. Tendon injuries, fractures of the metacarpals and phalanges and management of the wound are critical issues faced by a surgeon in dealing with such patients. A high incidence of suspicion is needed in dealing with these injuries effectively. Below we discuss various common and uncommon causes of bite injuries to the hand. Some of the cases discussed are rare, while some have resulted in disastrous complications, ranging from anaphylaxis to death.

\section{COMMON BITE INJURIES}

By far the most common cause of bite injury to the hand is dog bite [1,2], and we start of discussing these injuries. These are followed by cat bite injuries [1]. Human and

*Address correspondence to this author at the Department of Orthopaedic Surgery, Our Lady of Lourdes Hospital, Drogheda, Ireland;

Tel: (041) 9837601; Fax: (041) 9833868;

E-mail: anantmahapatr87@hotmail.com rodent bites are approximately 2-3\% each [1]. Dog bites are often high energy injuries resulting in fractures [3], whereas cat bites are more like puncture wounds resulting in tenosynovitis $[1,3]$. However even though the incidence of human bites was less, they often result in disastrous complications [4].

\section{Dog Bites}

One in 200 emergency room visits are due to dog bites [5]. Due to the numerous small compartments and the thin soft tissue covering over the bones and joints, bite wounds to the hand are more likely to become infected than bites to the arms, legs or face [6]. Various microorganisms are responsible for infected dog bites, but the commonest species is Pasteurella, with Pasteurella canis being the most common isolate [7]. However in certain studies Pasteurella was either very rarely found or was absent altogether [8, 9]. Tetanus cover, thorough debridement and delayed closure of the wound is the preferred treatment $[6,8]$. Pasteurella is resistant to Flucloxacillin and Erythromycin, and Coamoxiclav is the antibiotic recommended by the United Kingdom National Health Service as it covers all the microorganisms in the canine oral flora, and is active against penicillinase resistant Staphylococcus aureus and also against Pasteurella [3, 6].

\section{Cat Bites}

Cat bites account for about $5 \%$ of the bite injuries [1]. These injuries are more serious than dog bites [10]. The most common microorganism isolated is Pasteurella multocida and subspecies septica $[7,10]$. Co-amoxiclav is again the recommended antibiotic in these injuries $[3,6,11]$. A rare case of Pasteurella multocida causing osteomyelitis has been reported by the senior author, not in cat but in dog bites [12]. 
Puncture wounds caused by cat bites however do result in deeper infections like tenosynovitis [3].

Flexor tenosynovitis is a surgical emergency which requires incision and drainage of the sheath under antibiotic cover [3].

\section{Human Bites}

Human bites to the hand comprise of about $2 \%$ of cases [1]. Clenched fist injuries sustained due to fighting are a common cause. Any patient involved in a fight with an open wound on the knuckle should be carefully evaluated. These injuries are misleading most of the times. Owing to the mobility of the skin on the extensor aspect of the fist, during a clenched position and an extended position, the exact position of the deeper injury is missed. Clenched fist injuries often show a tooth mark at the inoculation site [13]. A radiograph is mandatory to look for a broken tooth. Such injuries should be allowed to heal by secondary intention by leaving them open [3].

The bacteriology of human bites consists of a mixed flora of aerobic and anaerobic microorganisms with one study stating that Group A streptococci was only present in human bite wounds [14]. Eikenella corrodens has been incriminated in many studies as a causative organism resulting in infections due to delayed presentation [15-17]. Michael Callaham in his study stated that closed fist injuries often present late and hence are associated with complications [1, 8]. He recommends Penicillin and Dicloxacillin to cover Eikenella corrodens and Staphylococcus aureus respectively, stating that Co-amoxiclav offers no benefit over Dicloxacillin, and is three times more expensive and with potentially dramatic complications [18]. More recent literature however supports the use of CoAmoxiclav, [3]. Management of human bite injuries consist of washing with soap, thorough debridement, administration of antibiotics and hospitalisation for 48 hours in certain cases $[19,20]$. Septic arthritis is a very serious complication requiring urgent referral. Similarly flexor tendon injuries (jersey finger) should be clinically diagnosed and referred to specialist centres for management [3]. Extensor tendon injuries should be thoroughly irrigated and any laceration more than 50\% should be repaired to avoid a delayed rupture [3].

\section{UNCOMMON BITE INJURIES}

Although the bite injuries discussed below are rare in certain parts of the World, they are seen more often in other parts. We discuss below, amongst other injuries, various snake bites and marine animal bites.

\section{Snake Bites}

Snake bites to the hands have been reported by many authors. Not only snakes living in the wild but also pet snakes have been responsible for such bite injuries. There is a case report of a young man deliberately getting bitten by his own rattle snake with the intention of committing suicide [21]. We came across many cases of snake bites where vipers were involved; the viper is a venomous snake belonging to the Crotalinae family. This family also includes rattlesnakes, bushmasters and lanceheads to name a few. Drastic complications have been reported following snake bites to hands, ranging from compartment syndrome to amputation of fingers. Schnecker reported a rare case of compartment syndrome of the hand and forearm following snake bite [21]. This patient had a haemorrhagic necrotizing inflammation and paraesthesia in the territory of the median nerve. Following a surgical procedure, the nerve function improved in three weeks and the circulation returned. Vigasio et al. reported a rare case of compartment syndrome of the intrinsic muscles of the hand in a young girl following a viper bite [22]. She developed these symptoms after 24 hours and underwent multiple dorsal and volar fasciotomies in order to get relief from the acute episode. Viper snake bites and their disastrous complications have been reported by many other authors. Valenta et al. reported of a rare case of a herpetologist who was bitten on his finger by a viper snake of the atherus genus [23]. This particular viper Proatheris superciliaris has been reported only twice in the literature. This patient had coagulopathy, thrombocytopenia and subsequently developed multiple organ failure [23].

There is no antisera for this venom hence the treatment was purely symptomatic. The patient was managed in an intensive care unit.

\section{Blood products were substituted and renal support was administered resulting in rapid recovery [23].}

Clark and Davidson reported on joint destruction following a digital intra-articular envenomation by Trimeresurus flavomaculatus mcgregori, a type of pit viper [24]. Cumpston in his review article about the need of fasciotomies following Crotalinae envenomations, feels that the current evidence does not support the use of fasciotomy or dermotomy following Crotalinae envenomation with elevated intracompartmental pressures. At present, early and adequate administration of crotaline Fab antivenin is the treatment of choice. Fasciotomy cannot be recommended until further well-designed investigations are completed [25]. Gary et al. reported a rare case of right popliteal vein thrombosis in a young healthy male adult following a viper bite in Austria.

\section{Subsequent activation of the complement system lead to thrombosis [26].}

Minkley et al. reported a case of a bite on the middle finger of a person by a sidewinder rattlesnake [27] where the patient was treated successfully by the administration of antivenom. Not everybody is lucky as the patient mentioned above. Ait Essi et al. reported three cases of amputation of fingers following a snake bite [28]. The authors stated that the virulence of the venom, its concentration in a small volume of tissue, and use of a tourniquet contributed to the poor outcome.

\section{Centipede Bites}

Centipedes (from Latin centi-, 'hundred', and -pede, 'foot') are found world over. They are arthropods, belonging to the class Chilopoda of the sub-phyllum Myriapoda. This seemingly small creature can be fatal. Uzel et al. reported drastic complications like necrotising fasciitis and cellulitis of the upper limb following centipede bites [29]. Double fang marks are the signs of a centipede bite. Thorough wound debridement and antibiotics have been reported to be beneficial. 
Similar case has been reported by Veraldi et al. where centipedes belonging to the Scolopendra subspinipes caused severe skin reactions to two patients. Both had complete remission with paracetamol and oral prednisolone [30].

\section{Horse Bites}

The authors have previously reported an unusual case of isolated dislocation of the pisiform following a horse bite in an eleven year old boy [31]. This patient was successfully treated non-operatively with the administration of appropriate antibiotics for the bite wound and cast application for the isolated dislocation of the pisiform.

\section{Marine Animal Bites}

Bite injuries to hand due to marine animals have been reported extensively in the literature. Such injuries can be sustained by domestic pet fish, during recreational or occupational fishing, or during exotic holidays where an array of wild sea life is encountered. Injury to the hand by the deceptive fish sting ray that lies hidden under a thin layer of sand and strikes with its tail have been reported by some authors. In the following section we have discussed injuries caused by marine animals. Al-Ajmi et al. reported:

A case of jellyfish sting leading to median nerve involvement. Electro-diagnostic studies confirmed a demyelinating lesion. The palmar branch of the median nerve was spared, with involvement of the motor and sensory branches. These were attributed to the local effects of the toxin released by the jelly fish. The patient improved with pregabaline which relieved him of his neuropathic pain [32].

Trickett et al. reported on a sting ray injury to the hand which presented late with a complaint of excruciating pain. Investigation in the form of a sonography revealed synovitis. A synovectomy performed subsequently confirmed the findings. The lumbrical muscles were necrotic with signs of chronic inflammation on histology [33].

Collins and Rose discussed an unusual case of an adult male patient who presented with toxic shock syndrome secondary from a fish tooth suffered while trout fishing [34]. Lee et al. reported a case series of eight patients where Stonefish envenomation of the hand in Singapore was discussed [35].

The authors recommend instituting early supportive treatment for the relief of pain. They feel that these envenomations do not have serious complications and most patients improve over time [35].

Adamicová et al. reported on a patient with granulomatous skin lesions following a bite by the predatory fish piranha [36]. The 60 year old patient had a lesion with granulomatous foci, some sarcoid-like, others with central necrosis, that were permeated with fibrinoid substance. Later on he, the patient also developed symptoms of carpal tunnel syndrome.

\section{Wasp Stings}

A wasp is an insect that is neither a bee nor an ant. It belongs to of the order Hymenoptera and suborder Apocrita.

Wasp stings are common during the warmer months when people are out of the confines of their homes. According to the Mayo clinic, $10 \%$ of people stung by wasps develop a 'large local reaction', and approximately 3\% of those stung can display severe allergic reactions that can become life threatening. In the following section we have discussed certain rare case reports of wasp stings where patients had serious complications. Sawyer et al. reported a case of a wasp sting leading to a compartment syndrome in a five year old child [37]. This patient underwent an emergent fasciotomy with delayed wound closure. He recovered full function of his hand at five months. The authors feel that local measures consisting of heat could have caused the compartment syndrome. Their recommendation is to have a cautious approach in treating these patients [37].

Calveri et al. reported a case of acute myocardial infarction in a 77 year old person following a wasp sting to the fifth finger of his left hand [38]. The authors feel that the hymenoptera venom could have caused the spasm of the coronary vessels, leading to the development of hypovolemic shock and hypotension [38].

\section{Lizard Bites}

Cantrell et al. reported a case of patient who was bit on his hand by a captive Mexican beaded lizard. His treatment constituted of administration of fluids and other symptomatic management using anti-emetics, steroids, etc. [39].

\section{Ferret Bites}

Iyengar et al. reported a case of Mycobacterium chelonae infection of the hand following a ferret bite [42]. The patient had chronic kidney disease with a background history of Type II diabetes. She had to undergo debridement of her fingers affected with pyogenic flexor tenosynovitis, under antibiotic cover. This patient later on had an osteomyelitis of the fingers and had to undergo another procedure. The authors feel that her altered immune status could have caused the events [40].

\section{DISCUSSION}

Although bite injuries are frequent, death as a result of them is rare. Dog bites as discussed earlier on are the commonest cause of bite injuries to the hand. Although dog bites to hands are not generally considered to be fatal, we came across one case report in literature that reported the death of a patient. Linton et al. reported:

\section{A case of fatal Capnocytophaga canimorsus septicaemia following a dog bite [41]. The oral flora of dogs has Capnocytophaga canimorsus, which was previouslyknown as dysgonic fermenter type 2 (DF-2) [41].}

The authors feel that this disease must be anticipated and dog bites appropriately managed to avoid the mortality 
associated with infection by this microorganism. Initial treatment includes appropriate prophylactic antibiotics and debridement, while early exchange transfusion and emergency amputation may be of value in fulminant cases. Injuries to the hand are significant injuries with implications not only for the patient but society as a whole [42, 43]. We feel that bite injuries to the hand should be treated with the respect they deserve. Each individual case is different and should be dealt with in a systematic and meticulous manner. A detailed history of the antecedent events which lead to the bite injury should be sought.

A cautious approach is necessary in cases where patient presents with laceration on the knuckle or simple sting marks on the hand. Patients with immune suppressive states are more prone to have serious complications and they should receive special care and attention. The occupation of the patient also plays an important role in coming to a diagnosis, for example a fisherman may present with marine animal bite injuries and we should plan our treatment accordingly. Similarly leisure, sporting and adventure activities are equally important and should be covered in the history. An unconscious swimmer may not be able to tell the story but his swimming hobbies and the natural aquatic habitat of that region will definitely help the curious physician to narrow down to the possible causative organism of the bite injury. Seasonal variations also play an important role, especially in incidents such as wasp stings. Warmer climate make people venture out and may result in relevant bite injuries. All of these factors must be considered when identifying such cases. Once these injuries are identified it is important that the treatment is timely, appropriate and evidence-based. Although the soft tissue is the more involved site, fractures should be managed appropriately, and there is a place in the management of these open fractures for external fixation [44, 45]. In addition, it is important to assess the outcome of these injuries using more objective measures that should include patient reported outcome measures [46, 47]. Finally in our opinion a multidisciplinary approach should be followed in treating such injuries and a strict protocol should be adhered to in the management of such injuries to optimise the patient's management.

\section{CONFLICT OF INTEREST}

We certify that there are no conflicts of interests with any financial organisation regarding the material discussed in this manuscript. No funding was received in support of this study.

\section{ACKNOWLEDGEMENTS}

Declared none.

\section{REFERENCES}

[1] Callaham, Michael L. Human and animal bites. Adv Emerg Nurs J 1982; 4(1): 1-15.

[2] Dunbar JD. Serious infection following wounds and bites of the hand. N Z Med J 1988; 101(847 Pt 1): 368-9.

[3] Cheung K, Hatchell A, Thoma A. Approach to traumatic hand injuries for primary care physicians. Can Fam Physician 2013; 59(6): 614-8.

[4] Iyidobi EC, Nwokocha AU, Nwadinigwe CU, Ugwoke KI. Aboveelbow amputation and death following human bite mismanaged by quacks: a case report and review of literature. Niger J Med 2012; 21(2): 249-51.

[5] Wiggins ME, Akelman E, Weiss APC. The management of dog bites and dog bite infections to the hand. Orthopedics 1994; 17(7): 617-23.

[6] Morgan M, Palmer J. Dog bites. Br Med J 2007; 334 (7590): 413

[7] Talan DA. Bacteriologic analysis of infected dog and cat bites. New Engl J Med 1999; 340 (2): 85-92.

[8] Callaham M. Prophylactic antibiotics in common dog bite wounds: a controlled study. Ann Emerg Med 1980; 9(8): 410-4.

[9] Boenning DA, Fleisher GR, Campos JM. Dog bites in children: epidemiology, microbiology, and penicillin prophylactic therapy. Am J Emerg Med 1983; 1(1): 17-21.

[10] Westling K. Cat bite wound infections: a prospective clinical and microbiological study at three emergency wards in Stockholm, Sweden. J Infect 2006; 53(6): 403-7.

[11] Lewis KT, Stiles M. Management of cat and dog bites. Am Fam Phys 1995; 52(2): 479.

[12] Mahapatra AN, Mulcahy D. Pasteurella multocida osteomyelitis following a dog bite. Ir J Med Sci 2002; 171(1): 56-6.

[13] Gonzalez MH, Papierski P, Hall RF Jr. Osteomyelitis of the hand after a human bite. J Hand Surg 1993; 18(3): 520-2.

[14] Brook I. Microbiology of human and animal bite wounds in children. Paed Infect Dis J 1987; 6(1): 29-32.

[15] Goldstein EJC. Bite wounds and infection. Clin Infect Dis 1992; 14(3): 633-40.

[16] Goldstein EJC, Barones MF, Miller TA. Eikenella corrodens in hand infections. J Hand Surg 1983; 8(5): 563-7.

[17] Schmidt DR, Heckman JD. Eikenella corrodens in human bite infections of the hand. J Trauma Acute Care Surg 1983; 23(6): 47882.

[18] Callaham M. Controversies in antibiotic choices for bite wounds Ann Emerg Med 1988; 17(12): 1321-9.

[19] Mann RJ, Hoffeld TA, Farmer CB. Human bites of the hand: Twenty years of experience. J Hand Surg 1977; 2(2): 97-104.

[20] Mennen U, Howells CJ. Human fight-bite injuries of the hand a study of 100 cases within 18 months. J Hand Surg 199; 16(4): 4315.

[21] Schnecker K. A rare cause of compartment syndrome of the forearm and hand following snake bite injury. Unfallchirurgie 1990; 16(3): 158-9.

[22] Vigasio A, Battiston B, De Filippo G, Brunelli G, Calabrese S. Compartmental syndrome due to viper bite. Arch Orthop Trauma Surg 1991; 110(3): 175-7.

[23] Valenta J, Stach Z, Fricova D, Zak J, Balik M. Envenoming by the viperid snake Proatheris superciliaris: a case report. Toxicon 2008; 52(2): 392-4.

[24] Clark RF, Davidson TM. Intraarticular envenomation by Trimeresurus flavomaculatus mcgregori resulting in joint destruction. Toxicon 1997; 35(6): 837-42.

[25] Cumpston, KL. Is there a role for fasciotomy in Crotalinae envenomations in North America? Clin Toxicol 2011; 49(5): 35165 .

[26] Gary T. Proximal lower limb vein thrombosis following Vipera berus hand bite. Vasa 2010; 39(2): 199-201.

[27] Minkley L, Overkamp D, Fischer J. Snakes as pets - consequences of an exotic hobby. Dtsch Med Wochenschr 2013; 138(50): 2619.

[28] Ait Essi F, Benhima MA, Abkari I, et al. Fingers amputation following snakebite: a report of three cases. Chir Main 2013; 32(2): 92-5.

[29] Uzel AP, Steinmann G, Bertino R, Korsaga A. Necrotizing fasciitis and cellulitis of the upper limb resulting from centipede bite: two case reports. Chir Main 2009; 28(5): 322-5.

[30] Veraldi S, Çuka E, Gaiani F. Scolopendra bites: a report of two cases and review of the literature. Int J Dermatol 2014. doi 10.1111/ijd.12434 [Epub ahead of print].

[31] Pradyumna R, Saeed N, Mahapatra AN. Isolated dislocation of pisiform in an 11-year-old, following a horse bite: a rare injury. Eur Orthop Traumatol 2013; 4(4): 273-5.

[32] Al-Ajmi AM, Jayappa S, Rousseff RT. Isolated severe median mononeuropathy caused by a jellyfish sting. J Clin Neuromuscul Dis 2013; 14(4): 188-93.

[33] Trickett R, Whitaker IS, Boyce DE. Sting-ray injuries to the hand: case report, literature review and a suggested algorithm for management. J Plast Reconstr Aesthet Surg 2009; 62(8): 270-3. 
[34] Collins AN, Rose WD. Toxic shock syndrome in an adult male secondary to puncture wound. W V Med J 2004; 100(6): 234-5.

[35] Lee JY, Teoh LC, Leo SP. Stonefish envenomations of the hand- a local marine hazard: a series of 8 cases and review of the literature. Ann Acad Med Singapore 2004; 33(4): 515-20.

[36] Adamicová K, Fetisovová Z, Strmenová V, Maarouf Z, Ondrejovic $\mathrm{P}$, Mad'ar R, Mellová Y. Granulomatous skin disease after an exotic injury. Cesk Patol 2003; 39(2): 80-4

[37] Sawyer JR, Kellum EL, Creek AT, Wood GW. Acute compartment syndrome of the hand after a wasp sting: a case report. J Pediatr Orthop B 2010; 19(1): 82-5.

[38] Calveri G, Bertelli Y, Caico SI, et al. Acute myocardial infarction after wasp sting. Ital Heart J Suppl 2002; 3(5): 555-7.

[39] Cantrell FL. Envenomation by the Mexican beaded lizard: a case report. J Toxicol Clin Toxicol 2003; 41(3): 241-4.

[40] Iyengar KP, Nadkarni JB, Gupta R, Beeching NJ, Ullah I, Loh WY. Mycobacterium chelonae hand infection following ferret bite. Infection 2013; 41(1): 237-41
[41] Linton DM. Fatal Capnocytophaga canimorsus (DF-2) septicaemia. A case report. S Afr Med J 1994; 84(12): 857-60.

[42] Malik A, Khan W. Editorial: recent advances and developments in hand surgery. Open Orthop J 2012; 6(1): 11-3.

[43] Malik AA, Yousaf N, Khan WS, Ihsan M, Ravenscroft M. Fractures of the wrist and hand. J Perioper Pract 2010; 20(2): 4854.

[44] Haughton DN, Jordan D, Malahias M, Hindocha S, Khan WS. Principles of hand fracture management. Open Orthop J 2012; 6(1): 43-53.

[45] Khan WS, Smitham PJ, Fahmy N. A modified technique of using the S-Quattro external finger fixation system- A case study. Ortop Traumatol Rehabil 2011. 13(4): 399-402.

[46] Khan WS, Jain R, Dillon B, Clarke L, Fehily M, Ravenscroft M. The ' $\mathrm{M}^{2}$ DASH'- Manchester-Modified Disability of the Arm, Shoulder and Hand Score. Hand (NY) 2008; 3(3): 240-4.

[47] Mafi P, Mafi R, Hindocha S, Griffin M, Khan WS. A systematic review of dynamometry and its role in hand trauma assessment. Open Orthop J 2012; 6: 95-102.

(C) Raval et al.; Licensee Bentham Open.

This is an open access article licensed under the terms of the Creative Commons Attribution Non-Commercial License (http://creativecommons.org/licenses/by-nc/3.0/) which permits unrestricted, non-commercial use, distribution and reproduction in any medium, provided the work is properly cited. 